\title{
Two-Dimensional Simulation of Flows in an Open Channel with Groin-Like Structures by iRIC Nays2DH
}

\author{
Md. Shahjahan Ali, Md. Milon Hasan, and Masuma Haque \\ Department of Civil Engineering, Khulna University of Engineering \& Technology, Khulna 9203, Bangladesh \\ Correspondence should be addressed to Md. Shahjahan Ali; bablu41@yahoo.com
}

Received 19 February 2017; Accepted 6 August 2017; Published 14 September 2017

Academic Editor: Jian G. Zhou

Copyright ( $2017 \mathrm{Md}$. Shahjahan Ali et al. This is an open access article distributed under the Creative Commons Attribution License, which permits unrestricted use, distribution, and reproduction in any medium, provided the original work is properly cited.

\begin{abstract}
This study presents the results obtained from the numerical simulation on turbulent flows around a single groin for different orientations. Here iRIC Nays2DH, which is based on 2D model, is used to simulate the flows in a straight open channel with groin of $45^{\circ}, 90^{\circ}$, and $135^{\circ}$ angled with the approaching flow. A depth-averaged $k$ - $\varepsilon$ model is used as turbulence closure model with finite differential advections as upwind scheme. The numerical results of velocity and bed shear stress profiles are compared with the available experimental data. Good agreements are found between experimental and calculated results. From the simulation, it is observed that the peak of velocity and bed shear stress is maximum at the position of head of groin when lateral distance $y / l=1$, where $l$ is the groin length. The position of maximum velocity and bed shear stress is found to be shifted towards downstream with increasing $y / l$. The maximum velocity and bed shear stress for $135^{\circ}$ groin are found lower than the other two cases for all the sections of $y / l$.
\end{abstract}

\section{Introduction}

The simulation of water flow and sediment transport in rivers has been the subject of many researches in the field of hydraulics and river engineering [1]. In hydraulics and coastal engineering, groins are very important structures for river navigation, coastal protection, and beach reclamation [2]. It is an elongated obstruction having one end on the bank of the stream and the other end projecting into the current. Groins have been used extensively all over the world as river training and bank protection structure to reduce the current along the stream bank, thus reducing the erosive capacity of the stream and in some cases inducing sedimentation between two groins. It can be built at right angles to the bank or current (normal/deflecting groin) or angled towards upstream (repelling groin) or angled towards downstream (attracting groin). The obstructed flow field in the downstream of a single groin or the flow field enclosed by two consecutive groynes is low velocity region compared to mainstream. This type of zone is generally termed as dead zone [3]. Flow velocity inside such kind of arrangement is lower than main channel. In addition to engineering applications, such structures increase the biodiversity of aquatic species by creating habitat and providing shelter for them. The main stream of a river, where the velocity is high, is not suitable for weak and small fishes. That is why the dead zone is a suitable shelter for them.

Many experimental and numerical researches have been performed to investigate the flow pattern and scouring around groins [4-7]. Those studies were carried out in different conditions in terms of groin length, groin inclination angle to the flow direction, permeable or impermeable states, submerged and nonsubmerged states, flow separation, recirculating length, and number of groins. The groin which is placed perpendicular to the river approaching flow causes narrowing and deviation of the flow and consequently this gives a complex three-dimensional form to flow around a groin $[4,5]$. However, dealing with the practical engineering problems, such as alluvial geomorphic processes, it is computationally efficient to use 2D models compared to 3D. In this study, 2D software called iRIC Nays2DH (available 
in http://www.i-ric.org) has been used which is based on Navier-Stokes equations to simulate the flows in an open channel with groin-like structures.

It is well known that the RANS (Reynolds Averaged Navier-Stokes) type turbulence models, such as two-equation model or Reynolds stress model, are the most popular tool used for practical engineering applications [8-10]. Because it requires less CPU time and computer memory compared to LES and DNS. Therefore, the clarification of the possibility, the limitation, and areas of improvement of RANS models should be still paid attention to. To resolve the Reynolds stress term which appeared in the averaged Navier-Stokes equations, the $k-\varepsilon$ model is one of the most frequently adopted ones $[10,11]$. However, the standard $k-\varepsilon$ model cannot produce satisfactory results for the flow field having high rate of strain and rotation $[12,13]$. In iRIC Nays $2 \mathrm{DH}$, a nonlinear $k-\varepsilon$ model is used to predict the turbulent flow field by capturing the anisotropic turbulence.

\section{Basic Equations of the Model}

iRIC (International River Interface Cooperative), pre- and postprocessing software application and framework for computational models of flow and sediment transport in rivers, is used in this study. The application is a Graphical User Interface (GUI) that allows the model user to build, run, and visualize the results of the system's computational models. The GUI provides tools for building both structured and unstructured grids, defining topography and other boundary conditions on the grid, and defining grid-dependent values such as grain size, vegetation, and obstacles by mapping measured values to the grid or by creating user-defined polygons with attributes of grid-dependent value. It combines the functionality of MD_SWMS, developed by the USGS (U.S. Geological Survey), and RIC-Nays, developed by the Foundation of Hokkaido River Disaster Prevention Research Center. The details of the model can be found in iRIC [14] and Jang and Shimizu [15].

For the analysis, the general curvilinear coordinate system is adopted, allowing direct consideration of complex boundaries and riverbed shapes. Basic equations of twodimensional plane flow at orthogonal coordinates $(x, y)$ are transformed into general coordinates $(\xi, \eta)$. By transforming the equations into general coordinates, it becomes possible to set a calculation mesh of any shape (in keeping with the boundary conditions). The basic equations in an orthogonal coordinate system $(x, y)$ are as follows [16].

\section{Equation of Continuity}

$$
\frac{\partial h}{\partial t}+\frac{\partial(h u)}{\partial x}+\frac{\partial(h v)}{\partial y}=0
$$

Equations of Motion

$$
\begin{aligned}
& \frac{\partial(u h)}{\partial t}+\frac{\partial\left(h u^{2}\right)}{\partial x}+\frac{\partial(h u v)}{\partial y}=-h g \frac{\partial H}{\partial x}-\frac{\tau_{x}}{\rho}+D^{x} \\
& \frac{\partial(v h)}{\partial t}+\frac{\partial(h u v)}{\partial x}+\frac{\partial\left(h v^{2}\right)}{\partial y}=-h g \frac{\partial H}{\partial y}-\frac{\tau_{y}}{\rho}+D^{y}
\end{aligned}
$$

where $h$ is water depth, $t$ is time, $u$ is velocity in the $x$ direction, $v$ is velocity in the $y$ direction, $g$ is gravitational acceleration, and $H$ is the total water depth. Here, the bed shear stresses in $x$ and $y$ directions $\left(\tau_{x}\right.$ and $\tau_{y}$ ) are expressed by using coefficient of riverbed shearing force $C_{f}$ as

$$
\begin{aligned}
& \frac{\tau_{x}}{\rho}=C_{f} u \sqrt{u^{2}+v^{2}}, \\
& \frac{\tau_{y}}{\rho}=C_{f} v \sqrt{u^{2}+v^{2}} .
\end{aligned}
$$

In the model, the bottom friction is set using Manning's roughness parameter. The coefficient of riverbed shearing force $C_{f}$ is estimated by Manning's roughness parameter $n_{m}$ as follows:

$$
C_{f}=\frac{g n_{m}^{2}}{\sqrt[3]{h}}
$$

The diffusion terms in $x$ and $y$ directions are expressed as (5) and (6), respectively. Here, $v_{t}$ is the eddy viscosity coefficient.

$$
\begin{aligned}
& D^{x}=\frac{\partial}{\partial x}\left[v_{t} \frac{\partial(u h)}{\partial x}\right]+\frac{\partial}{\partial y}\left[v_{t} \frac{\partial(u h)}{\partial y}\right], \\
& D^{y}=\frac{\partial}{\partial x}\left[v_{t} \frac{\partial(v h)}{\partial x}\right]+\frac{\partial}{\partial y}\left[v_{t} \frac{\partial(v h)}{\partial y}\right] .
\end{aligned}
$$

2.1. Depth-Averaged $k$ - $\varepsilon$ Model. The eddy viscosity coefficient $v_{t}$ in the standard $k-\varepsilon$ model is expressed by the following equation:

$$
v_{t}=C_{\mu} \frac{k^{2}}{\epsilon},
$$

where $C_{\mu}$ is a model constant. $k$ and $\epsilon$ are obtained by the following equations [16]:

$$
\begin{aligned}
\frac{\partial k}{\partial t}+u \frac{\partial k}{\partial x}+v \frac{\partial k}{\partial y}= & \frac{\partial}{\partial x}\left(\frac{v_{t}}{\sigma_{k}} \frac{\partial k}{\partial x}\right)+\frac{\partial}{\partial y}\left(\frac{v_{t}}{\sigma_{k}} \frac{\partial k}{\partial y}\right)+P_{h} \\
& +P_{k v}-\epsilon \\
\frac{\partial \epsilon}{\partial t}+u \frac{\partial \epsilon}{\partial x}+v \frac{\partial \epsilon}{\partial y}= & \frac{\partial}{\partial x}\left(\frac{v_{t}}{\sigma_{\epsilon}} \frac{\partial \epsilon}{\partial x}\right)+\frac{\partial}{\partial y}\left(\frac{v_{t}}{\sigma_{\epsilon}} \frac{\partial \epsilon}{\partial y}\right) \\
& +C_{1 \epsilon} \frac{\epsilon}{k} P_{h}+P_{\epsilon v}-C_{2 \epsilon} \frac{\epsilon^{2}}{k}
\end{aligned}
$$

where $C_{1 \epsilon}, C_{2 \epsilon}, \sigma_{k}$, and $\sigma_{\epsilon}$ are model constants whose respective values are shown in Table 1 . Note that $P_{k v}$ and $P_{\epsilon v}$ are calculated with the following equations:

$$
\begin{aligned}
& P_{k v}=C_{k} \frac{u_{*}^{3}}{h}, \\
& P_{\epsilon v}=C_{\epsilon} \frac{u_{*}^{4}}{h^{2}} .
\end{aligned}
$$




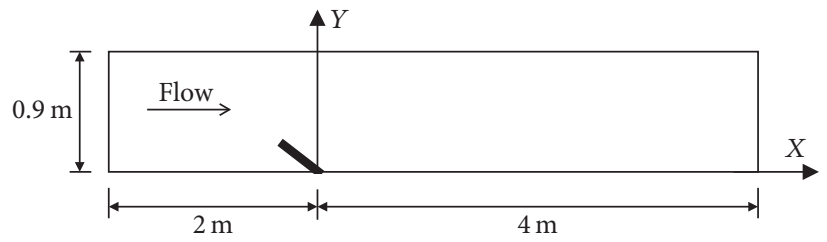

FIgURE 1: Groin orientation for $45^{\circ}$ angled to the direction of flow (case 1).

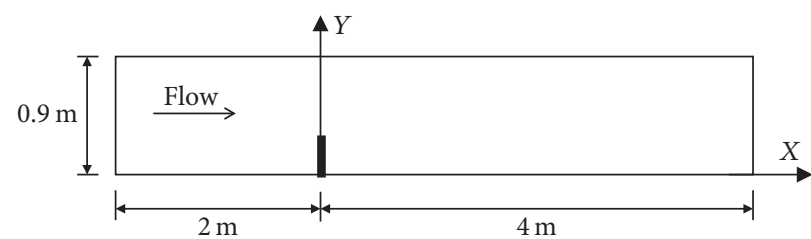

Figure 2: Groin orientation for $90^{\circ}$ angled to the direction of flow (case 2).

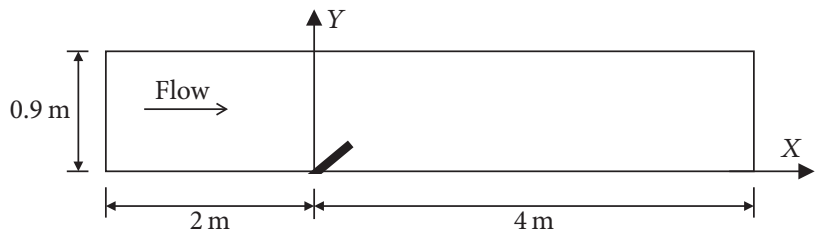

Figure 3: Groin orientation for $135^{\circ}$ angled to the direction of flow (case 3).

TABLE 1: Model constants for nonlinear $k-\varepsilon$ model [16].

\begin{tabular}{ccccc}
\hline$C_{\mu}$ & $C_{1 \varepsilon}$ & $C_{2 \varepsilon}$ & $\sigma_{k}$ & $\sigma_{\varepsilon}$ \\
\hline 0.09 & 1.44 & 1.92 & 1.0 & 1.3 \\
\hline
\end{tabular}

\section{Numerical Tests}

3.1. Flow Domain and Hydraulic Parameters. The hydraulic parameters for different test cases that were simulated are shown in Table 2. The parameters for case 2 of flows in a straight open channel with groin of $90^{\circ}$ angle to the direction of flow were taken the same as the experiments by Rajaratnam and Nwachukwu [7]. In their experiments, a $37 \mathrm{~m}$ long, $0.9 \mathrm{~m}$ wide, and $0.76 \mathrm{~m}$ deep flume with smooth bed and sides were used. The groin was an aluminum plate with $3 \mathrm{~mm}$ thickness and $152 \mathrm{~mm}$ length and was projected partly above the water surface. The hydraulic parameters for the $45^{\circ}$ and $135^{\circ}$ angled groin are the same as case 2 .

Figure 2 shows the sketch of the flow domain for flows in a straight open channel with groin of $90^{\circ}$ angled to the direction of flow which was performed under the same conditions of the experiments conducted by Rajaratnam and Nwachukwu [7]. Figures 1 and 3 show the sketch of the flow domain for $45^{\circ}$ and $135^{\circ}$ which were performed under the same conditions as case 2 . For all these cases, $120 \times 20$ grids were used considering fixed bed condition. Figure 4 shows a sample of computational mesh that consists of 120 grids in the longitudinal direction and 20 grids in transverse directions.

For all the cases of numerical simulation, the computational domain was $6 \mathrm{~m}$ in length and $0.9 \mathrm{~m}$ in width. The upstream and downstream boundaries were located at $2 \mathrm{~m}$ and $4 \mathrm{~m}$ away from the groin, respectively. The constant discharge at upstream was $0.043 \mathrm{~m}^{3} / \mathrm{s}$, and at the downstream the constant flow depth was $0.189 \mathrm{~m}$. Manning's roughness coefficient $n=0.01$ and the time step $\Delta t=0.003 \mathrm{sec}$ are assigned in the present computation. The simulations are performed in fixed bed condition with bottom slope, $S_{o}=$ 0.001 .

Quanhong and Pengzhi [17] also used the same experimental data of Rajaratnam and Nwachukwu [7] to validate their model. Governing equations of their model were shallow water equations and depth-averaged $k-\varepsilon$ model as the turbulence model. According to Quanhong and Pengzhi [17] model, the computational domain was $6 \mathrm{~m}$ in length and $0.9 \mathrm{~m}$ in width. Flow flux of $0.047817 \mathrm{~m}^{2} / \mathrm{s}$ and water depth of $0.189 \mathrm{~m}$ are specified at the upstream and downstream boundaries, respectively. For the same flow geometry and hydraulic conditions, Sarveram et al. [2] also simulated the flow field around $90^{\circ}$ groin using semi-implicit semiLagrangian method and compared their computed results with the Rajaratnam and Nwachukwu's experimental result. In the present study, the simulated flow field is compared with previous experimental results of Rajaratnam and 
TABLE 2: Hydraulic parameters for the simulated cases.

\begin{tabular}{lccccccr}
\hline Cases & $\begin{array}{c}\text { Groin } \\
\text { position }\end{array}$ & $\mathrm{U} / \mathrm{S}$ & $\mathrm{D} / \mathrm{S}$ & $W(\mathrm{~m})$ & $Q_{o}\left(\mathrm{~m}^{3} / \mathrm{s}\right)$ & $h_{o}(\mathrm{~m})$ & $S_{o}$ \\
\hline Case 1 & $45^{\circ}$ & 2 & 4 & 0.9 & 0.043 & 0.189 & 0.001 \\
Case 2 & $90^{\circ}$ & 2 & 4 & 0.9 & 0.043 & 0.189 & 0.001 \\
Case 3 & $135^{\circ}$ & 2 & 4 & 0.9 & 0.043 & 0.189 & 0.001 \\
\hline
\end{tabular}

Here, $L=$ length of the straight channel, $W=$ width of channel, $Q_{o}=$ upstream discharge, $h_{o}=$ water depth at downstream, $S_{o}=$ channel slope, and $n=$ Manning's roughness coefficient.

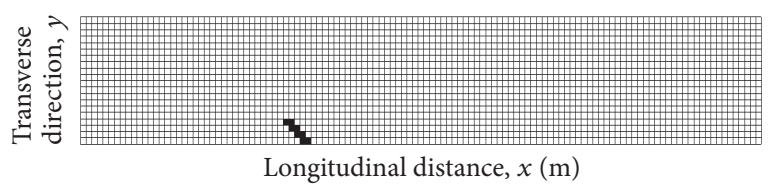

FIGURE 4: Plan of input grid for simulation of flow around groin with $45^{\circ}$ angle (case 1).

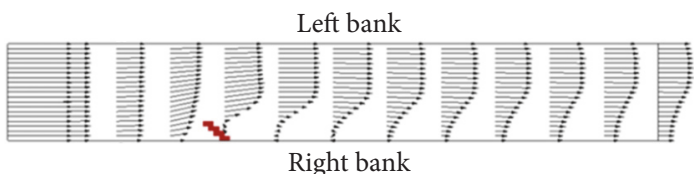

(a)

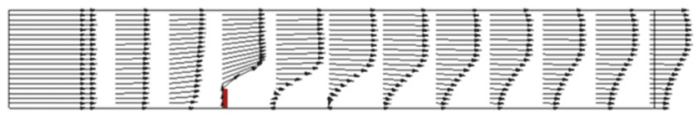

(b)

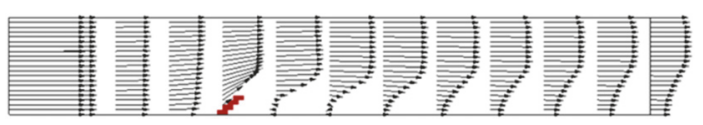

(c)

FIGURE 5: Computed velocity vector for (a) case 1, (b) case 2, and (c) case 3 developed by iRIC Nays2DH.

Nwachukwu [7] as well as previous simulation results of Quanhong and Pengzhi [17] and Sarveram et al. [2].

3.2. Computational Scheme. The governing equations for mean velocities and turbulent flows were discretized with the finite difference method based on full staggered boundary fitted coordinate system. The basic equations are discretized as fully explicit forms and solved successively with the time increment step by step. It is solved using iterative procedure at each time step. Constant discharge at upstream and constant depth with zero velocity gradients were given as downstream boundary conditions. Finite difference scheme was used for the solution of the equations, where the nonlinear convection terms were discretized with the upwind scheme.

\section{Simulated Flow Field}

Figures 5 and 6 show the predicted velocity vector of the flow field around the groin for different angles with the flow. For all the cases, the model is found to reproduce the general flow features of the flow field around the groin successfully. From the simulated results, it is seen that at the upstream boundary the flow is uniform and hence the flow vectors are straight and parallel to bank. However, when the flow approaches the groin, the flow is deviated towards the left bank compared to the right due to obstruction of flow by the groin. A recirculation zone is observed just downstream region of the groin for all the cases.

Figure 7 shows the streamline around a groin, which is obtained by the present study. From the streamline contour, it is also found that at the position of groin head the flow is deviated towards the opposite bank and at the downstream of the groin there is a circulation. Figures 6 and 7 depict that for case 1 ( $45^{\circ}$ groin) the deviations of vectors and streamlines are higher compared to case 2 ( $90^{\circ}$ groin). $135^{\circ}$ groin for case 3 shows the least deviation compared to other cases. The length of circulation zone at downstream of the groin is also higher for case 1 and lower in case 3.

\section{Comparison of Simulated Results with Previous Studies}

Simulated results such as computed velocity profiles and bed shear stress profiles for $90^{\circ}$ groins (case 2) are compared with 


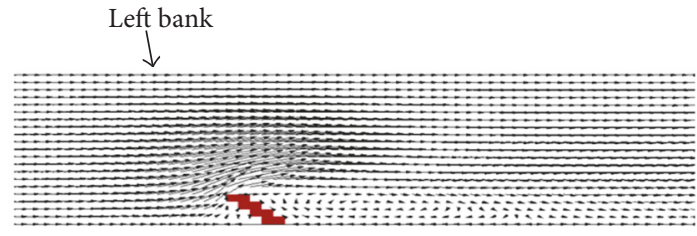

(a)

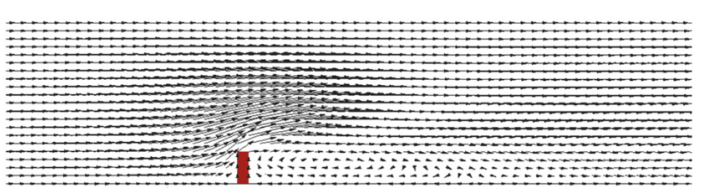

(b)

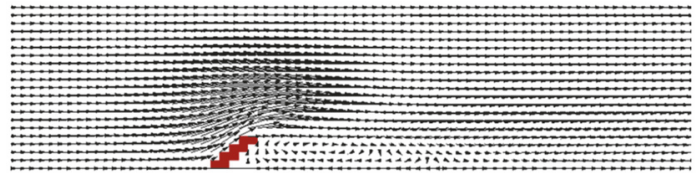

(c)

FIGURE 6: Computed velocity vector and recirculation zone around groin for (a) case 1, (b) case 2, and (c) case 3 developed by iRIC Nays2DH.

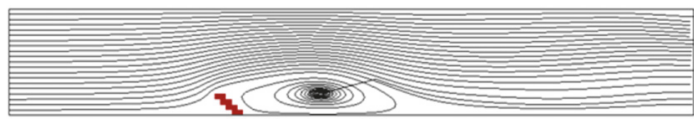

(a)

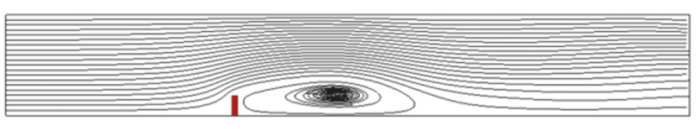

(b)

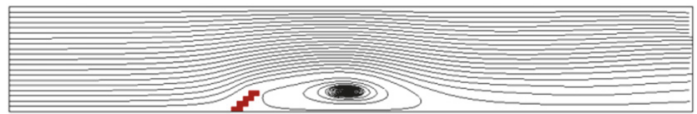

(c)

FIGURE 7: Streamline around a groin for (a) case 1, (b) case 2, and (c) case 3 developed by iRIC Nays2DH.

previous experimental as well as available previous simulation results. The comparison is described in the following sections.

5.1. Velocity Profiles. For $90^{\circ}$ groins, the resultant velocity profiles are compared with available experimental results measured at $y / l=1.0,1.5,2.0,3.0$, and 4.0 , where $l=152 \mathrm{~mm}$ is the length of the groin. Figure 8 shows the comparison of velocity profiles for different lateral distances $(y / l)$. Here, the initial flow velocity and water depth were $U_{o}=0.253 \mathrm{~m} / \mathrm{s}$ and $H=0.189 \mathrm{~m}$, respectively. In the figure, all the velocities were normalized by $U_{o}$. In the figure, $x / l=0$ indicated the groin position along flume direction.

Good agreements are found between experimental and calculated results. For the velocity profiles, the only large discrepancy occurs at $y / l=2$, where the calculated results underpredict the experimental data in the downstream zone of the groin. It is noticed that the numerical results reported by Quanhong and Pengzhi [17] and Sarveram et al. [2] also underpredicted the experimental data largely in this region. This may be due to the very high velocity gradient arising in this region which makes the depth-averaged model inapplicable. Otherwise, the possible reason may come from the experimental measurement errors in this region [17].
5.2. Bed Shear Stress Profiles. Figure 9 shows comparison of bed shear stress profiles $(\tau)$ of predicted results with the available previous studies. In the figure, all the shear stresses are normalized by $\tau_{o}=0.1293 \mathrm{~N} / \mathrm{m}^{2}$. The comparison between the numerical results and experimental data shows reasonable agreement. For the lateral sections up to $y / l=$ 2 , the simulated results underpredict the downstream shear stress slightly. The numerical results reported by Quanhong and Pengzhi [17] also show similar prediction. It may be the deficiency of the depth-averaged model to account for the high velocity gradient arising very near to the groin.

\section{Simulation Results for Different Cases}

6.1. Predicted Velocity Profiles. Figure 10 shows the comparison among predicted velocity profiles $(W)$ for case 1 , case 2 , and case 3 . For each case, the longitudinal velocity profiles are compared at a lateral position of $y / l=1.0,1.5,2.0,3.0$, and 4.0. In the figure, all the velocities are normalized by $U_{0}$ $=0.253 \mathrm{~m} / \mathrm{s}$ and here $x / l=0$ indicates the groin position in the longitudinal direction. The comparisons among the three cases show reasonable differences. Along line $y / l=1$, the peak of velocities is found at longitudinal distances of $x / l=$ $-0.28,0.0$, and 0.56 for case 1 , case 2 , and case 3 , respectively. For $y / l=1.0$, in all the cases, the velocity is found to be 

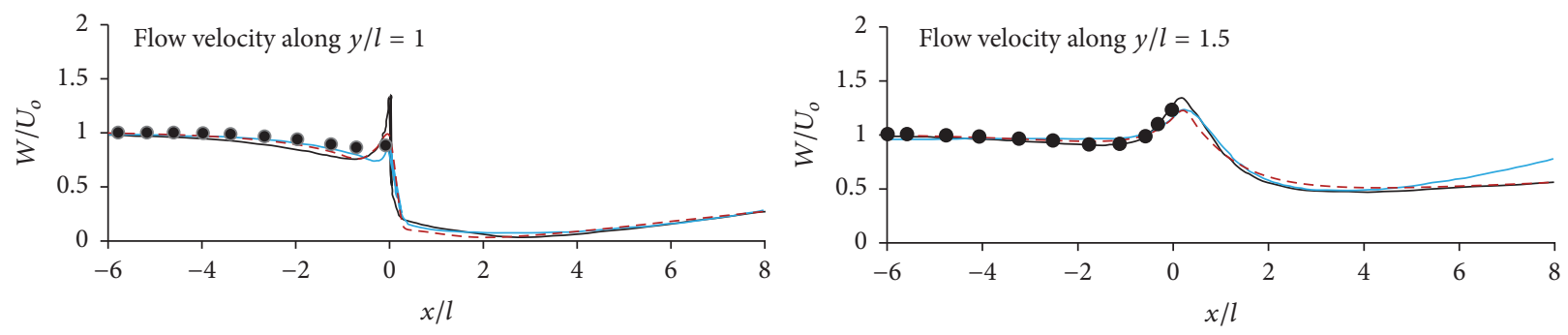

- Measured (Rajaratnam and Nwachukwu, 1983)

- Computed (Quanhong and Pengzhi, 2007)

_ Computed (Sarveram et al., 2012)

- - - Computed (present study)

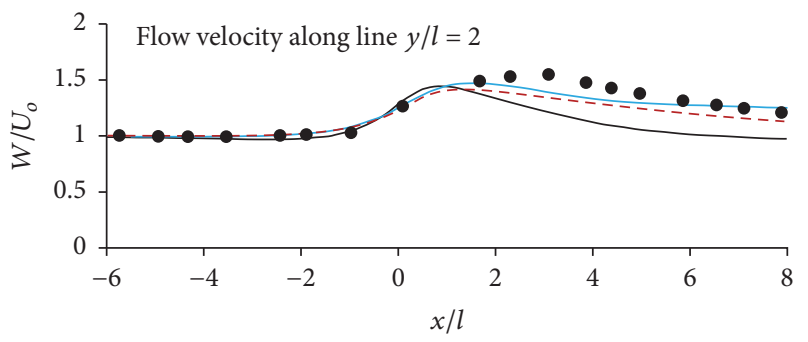

- Measured (Rajaratnam and Nwachukwu, 1983)

_ Computed (Quanhong and Pengzhi, 2007)

_ Computed (Sarveram et al., 2012)

- - - Computed (present study)

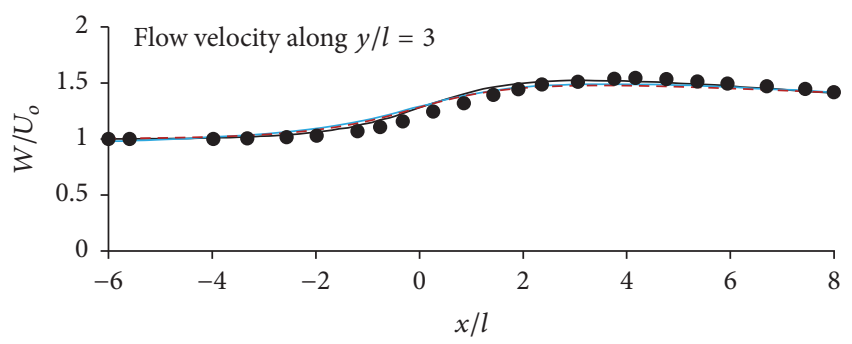

- Measured (Rajaratnam and Nwachukwu, 1983 )

- Measured (Rajaratnam and Nwachukwu, 1983)

— Computed (Quanhong and Pengzhi, 2007)

_ Computed (Sarveram et al., 2012)

- - - Computed (present study)

— Computed (Quanhong and Pengzhi, 2007)

_ Computed (Sarveram et al., 2012)

- - - Computed (present study)

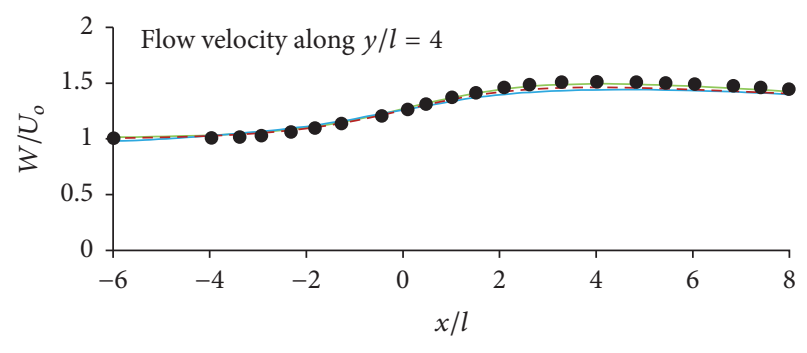

- Measured (Rajaratnam and Nwachukwu, 1983 ) Computed (Quanhong and Pengzhi, 2007)

_ Computed (Sarveram et al., 2012)

- - - Computed (present study)

FIGURE 8: Comparison of resultant velocity profiles $(W)$ with the available previous studies for $90^{\circ}$ groin (case 2).

decreased from upstream velocity just before the position of groin head. In other words, in addition to the circulation zone at downstream of groin, a small low velocity zone is observed just upstream of groin at right bank. Along the line $y / l=$ 1.5 , the peak of velocities is found at longitudinal distances of $x / l=-1.0,0.22$, and 0.67 for case 1 , case 2 , and case 3 , respectively. These peak velocities are found to be decayed with the longitudinal distance $x / l$. For $y / l=2$, the peaks of velocities are found at a distance of $x / l=-0.11,1.22$, and 2.54 for case 1 , case 2 , and case 3 , respectively. For $y / l \geq 2$, the decay of velocity along the downstream is found to be slower compared to the region $y / l \leq 1.5$. Along the line $y / l=3$, the peak of velocities is found at longitudinal distances of $x / l=2.87,3.53$, and 3.88 for case 1 , case 2 , and case 3 , respectively. Along the line $y / l=4$, the peak of velocities is found at longitudinal distances of $x / l=3.33,3.89$, and 4.44 for case 1 , case 2 , and case 3 , respectively.

From the figures, it is observed that the peak of velocity is found maximum at the position of head of groin when $y / l=1$. However, this position of maximum velocity is found to be shifted towards downstream with increasing $y / l$. The maximum velocity for case 3 is found lower than the other two cases for all the sections of $y / l$. However, $W / U_{o}$ for $90^{\circ}$ groin is found maximum for $y / l \leq 2$; and for $y / l>2$, the velocity is maximum for $45^{\circ}$ angled groin.

6.2. Predicted Bed Shear Stress Profiles. Figure 11 shows the predicted bed shear stress profiles $(\tau)$ of the proposed model for case 1 , case 2 , and case 3 . For each case, the longitudinal 

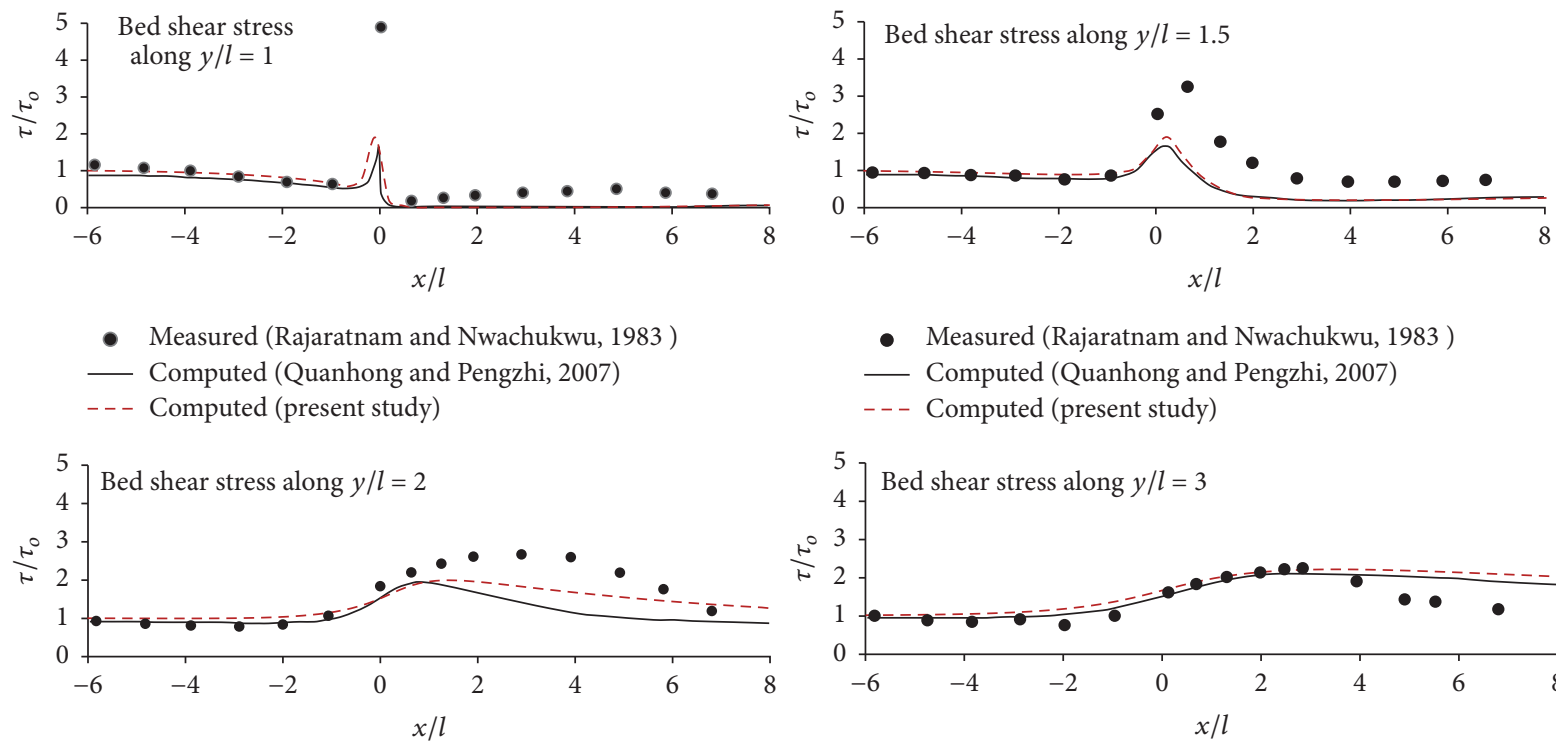

- Measured (Rajaratnam and Nwachukwu, 1983 )

- Computed (Quanhong and Pengzhi, 2007)

- - - Computed (present study)

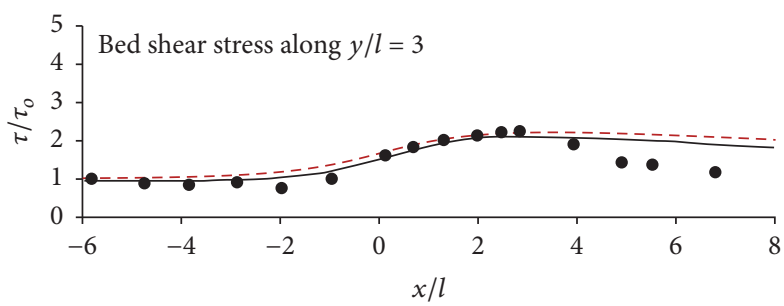

- Measured (Rajaratnam and Nwachukwu, 1983 )

- Computed (Quanhong and Pengzhi, 2007)

- - Computed (present study)

- Measured (Rajaratnam and Nwachukwu, 1983)

Computed (Quanhong and Pengzhi, 2007)

- - - Computed (present study)

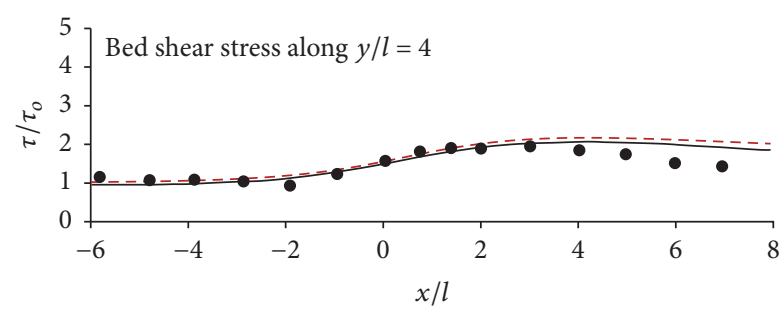

- Measured (Rajaratnam and Nwachukwu, 1983)

— Computed (Quanhong and Pengzhi, 2007)

- - - Computed (present study)

FIgURE 9: Comparison of bed shear stress profiles $(\tau)$ with the available previous studies for $90^{\circ}$ groin (case 2).

shear stress profiles are compared at a lateral position of $y / l$ $=1.0,1.5,2.0,3.0$, and 4.0. In the figure, all the shear stresses are normalized by $\tau_{o}=0.1293 \mathrm{~N} / \mathrm{m}^{2}$, which is the value of upstream region. Here, $x / l=0$ is the groin position along longitudinal direction. The profiles of bed shear stress are found in similar pattern of velocity profiles. For different values of $y / l$, the peak of shear stresses is found at the same longitudinal distances $(x / l)$ as reported in velocity profiles. For $y / l=1.0$, in all the cases, the shear stress is found to be decreased from its upstream value just before the position of groin head.

From the figures, it is observed that the peak of bed shear stress is found maximum at the position of head of groin when $y / l=1$. However, this position of maximum bed shear stress is found to be shifted towards downstream with increasing $y / l$. These peak shear stresses are found to be decayed with the longitudinal distance $x / l$. However, for $y / l \geq 2$, the decay of shear stress along the downstream is found to be slower compared to the region $y / l \leq 1.5$. The maximum bed shear stress for case 3 is found lower than the other two cases for all the sections of $y / l$. However, $\tau / \tau_{o}$ for $90^{\circ}$ groin is found maximum for $y / l \leq 1.5$, and for $y / l \geq 2$, the velocity is maximum for $45^{\circ}$ angled groin.

6.3. Velocity and Bed Shear Stress Contour. Figure 12 shows the simulated velocity contour in shaded color for case 1, case 2 , and case 3 , respectively. The results are found to be similar in nature. For all the cases, the velocity contour along the left bank is higher than the right bank at the downstream region of the groin; it indicates the deflection of flow towards right bank and sheltering of flow by groin at east bank. The downstream circulation zone is found to be larger for $45^{\circ}$ groin compared to $90^{\circ}$ groin; similarly the circulation zone for $90^{\circ}$ groin is found to be larger compared to $135^{\circ}$ groin.

In the figure, the flow field is seen to be divided into four distinct regions: (i) the uniform flow at upstream end, (ii) big circulation of low velocity zone at the downstream of the groin created due to sheltering of groin where the velocity 

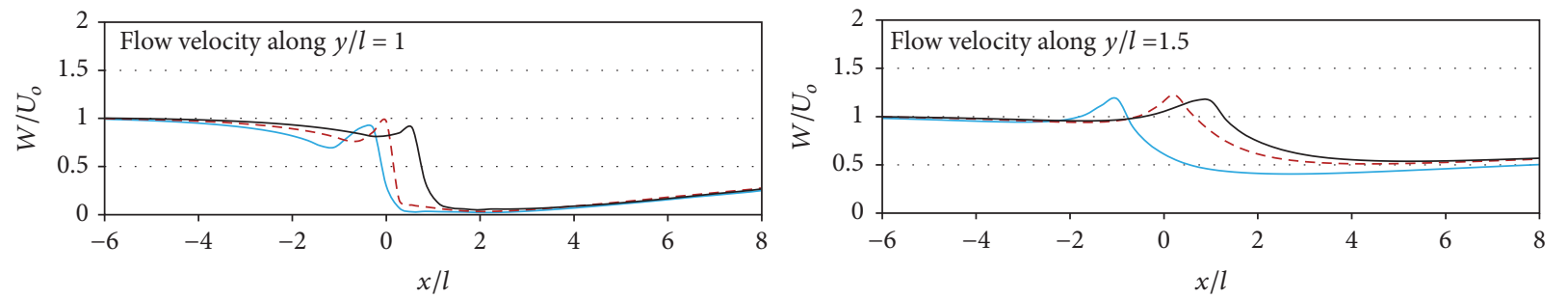

Computed (case 1)
--- Computed (case 2)
- Computed (case 3)

- Computed (case 1)

- - - Computed (case 2)

_ Computed (case 3)
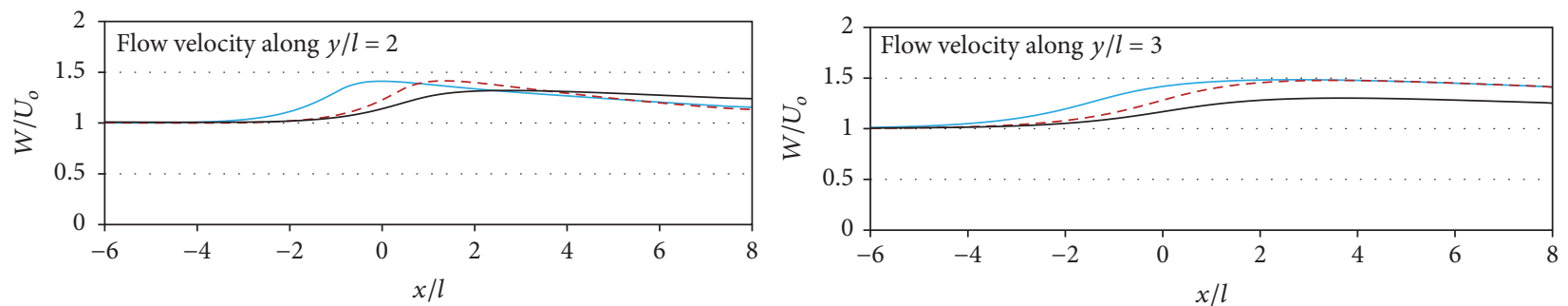

- Computed (case 1)

- - - Computed (case 2)

— Computed (case 3)

- Computed (case 1)

- - - Computed (case 2)

_ Computed (case 3)

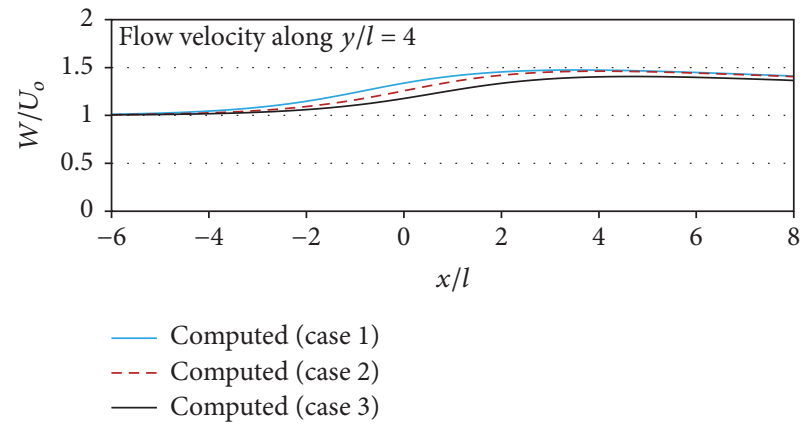

FIGURE 10: Comparison between resultant velocity profiles $(W)$ of present study for case 1 , case 2 , and case 3 along lateral distance, $y / l=1$, $1.5,2,3$, and 4 .

is zero in the center of the circulation zone, (iii) a small low velocity zone near the foot at the upstream of groin, and (iv) high velocity zone opposite to the circulation zone created due to the deflected flow. The high velocity zone is found to be decayed towards downstream and the low velocity in circulating zone is found to be regained.

Figure 13 shows the simulated bed shear stress contour in shaded color for case 1 , case 2 , and case 3 , respectively. The results are found to be similar in nature. Like the velocity contour, for all the cases, the shear stress contour along the left bank is higher than the right bank at the downstream region of the groin. Four distinct flow regions as described in velocity contour are also clearly visible in the contour of shear stress.

\section{Conclusions}

This simulation has provided us with detailed information regarding the flow pattern, the velocity, and bed shear stress profiles of a groin. This adds to the effort of work done by others on different types of groins. In the simulation, the general flow features around a groin is reproduced successfully. The flow field is found to be divided into four distinct regions: (i) the uniform flow at upstream end, (ii) big circulation of low velocity zone at the downstream of the groin created due to sheltering of groin where the velocity is zero in the center of the circulation zone, (iii) a small low velocity zone near the foot at the upstream of groin, and (iv) high velocity zone opposite to the circulation zone created due to the deflected flow. The high velocity zone is found to be decayed towards downstream and the low velocity in circulating zone is found to be regained.

The computed velocity and bed shear stress profiles of present study are compared among case 1 , case 2 , and case 3 . From the simulation, it is observed that the peak of velocity and bed shear stress is found maximum at the position of head of groin when lateral distance $y / l=1$, where $l$ is the groin length. The position of maximum velocity and bed shear stress is found to be shifted towards downstream with increasing $y / l$. The maximum velocity and bed shear stress for $135^{\circ}$ groin are found lower than the other two cases for all 

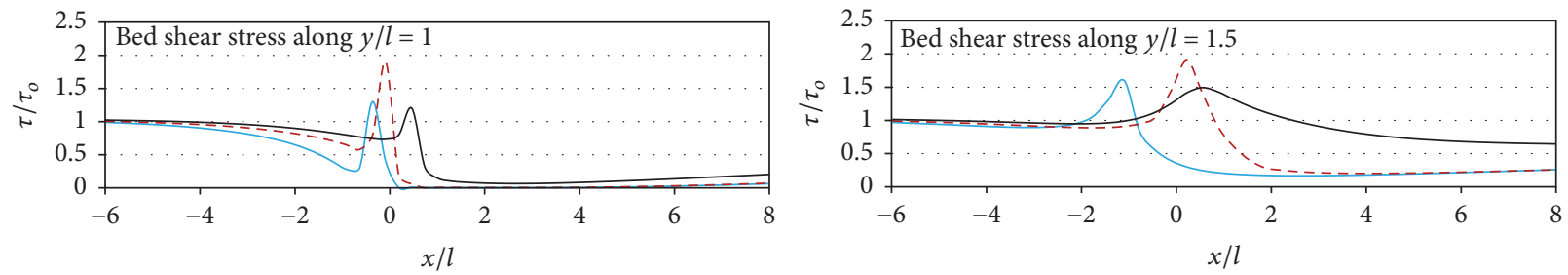

_ Computed (case 1)

_ Computed (case 1)

- - - Computed (case 2)

- - Computed (case 2)

- Computed (case 3)
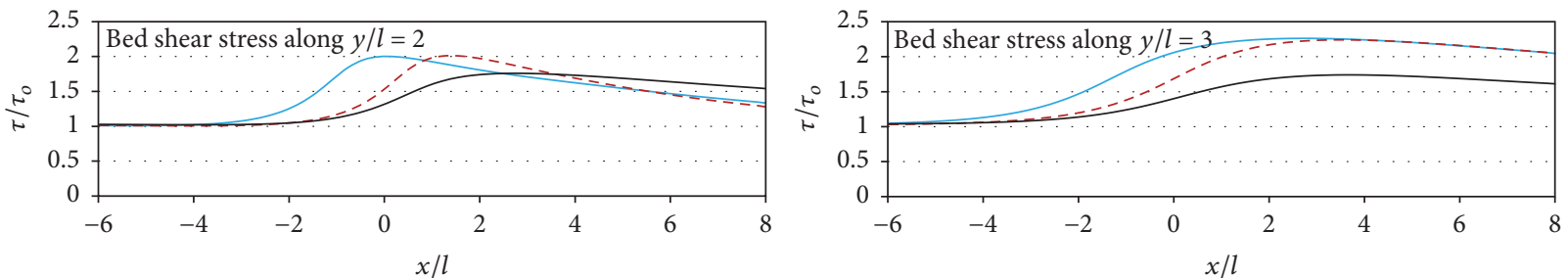

- Computed (case 1)

- - - Computed (case 2)

_ Computed (case 3)

_ Computed (case 1)

- - Computed (case 2)

— Computed (case 3)

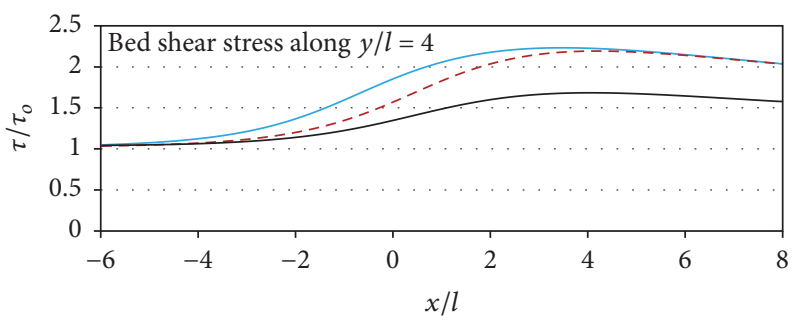

— Computed (case 1)

- - Computed (case 2)

_ Computed (case 3)

FIGURE 11: Comparison between computed bed shear stress profiles $(\tau)$ of proposed model for case 1, case 2, and case 3 along lateral distance, $y / l=1,1.5,2,3$, and 4 .

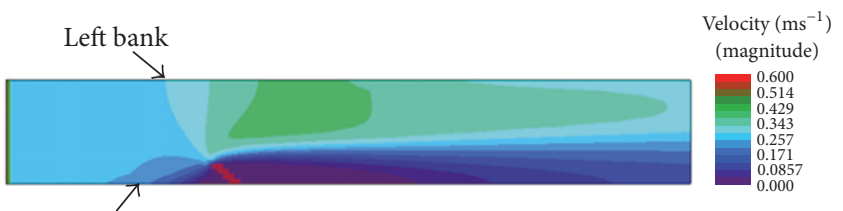

Right bank

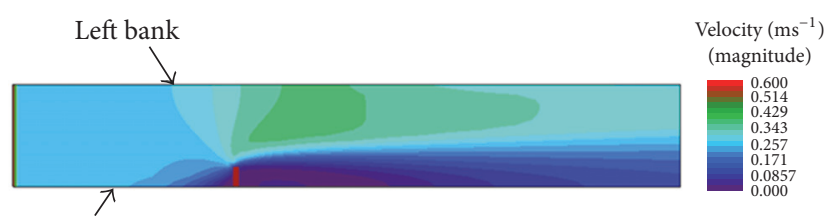

Right bank

(a)

(b)

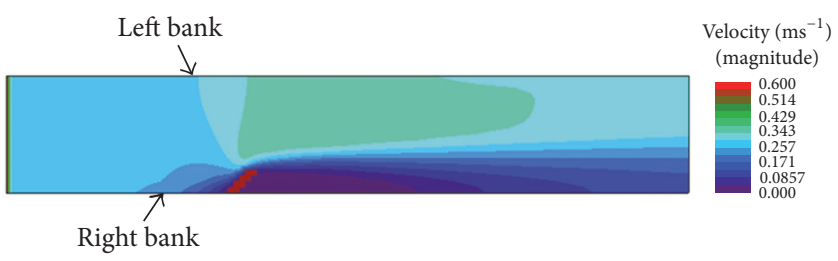

(c)

FIGURE 12: Velocity contoured around a groin for (a) case 1, (b) case 2, and (c) case 3 at the end of simulation by iRIC Nays2DH. 


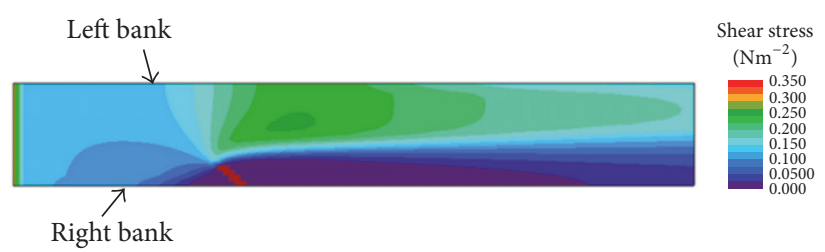

(a)

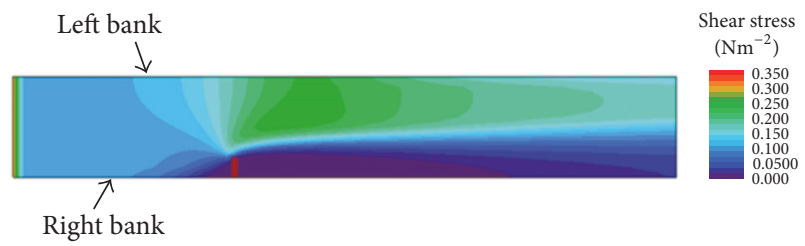

(b)

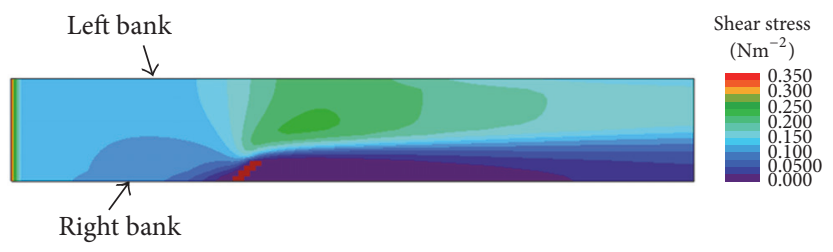

(c)

FIGURE 13: Bed shear stress contour around a groin for test (a) case 1, (b) case 2, and (c) case 3 at the end of simulation by iRIC Nays2DH.

the sections of $y / l . W / U_{o}$ and $\tau / \tau_{o}$ for $90^{\circ}$ groin are found maximum for $y / l \leq 2$, and for $y / l>2$, the velocity and bed shear stress are maximum for $45^{\circ}$ angled groin. The downstream circulation zone is found to be larger for $45^{\circ}$ groin compared to $90^{\circ}$ groin; similarly, the circulation zone for $90^{\circ}$ groin is found larger compared to $135^{\circ}$ groin.

In order to validate the present model, the computed results are compared with previous numerical and experimental results. The comparison between numerical and experimental results showed that except in areas where strong downward flow is observed there are good agreements between experimental and calculated results.

\section{Conflicts of Interest}

The authors declare that there are no conflicts of interest regarding the publication of this paper.

\section{References}

[1] L. G. T. De Azevedo, T. K. Gates, D. G. Fontane, J. W. Labadie, and R. L. Porto, "Integration of water quantity and quality in strategic river basin planning," Journal of Water Resources Planning and Management, vol. 126, no. 2, pp. 85-97, 2000.

[2] H. Sarveram, A. Shamsai, and M. A. Banihashemi, "Twodimensional simulation of flow pattern around a groyne using semi-implicit semi-Lagrangian method," International Journal of the Physical Sciences, vol. 7, no. 20, 2012.

[3] T. YiQun, Z. Hua, and W. YuanDong, "Characteristics of strain accumulation of reinforced soft clay around tunnel under subway vibration loading," Journal of Tongji University. Natural Science, vol. 39, no. 7, pp. 972-977, 2011.

[4] M. Vaghefi, M. Ghodsian, and S. A. A. S. Neyshabouri, "Experimental study on scour around a T-shaped spur dike in a channel bend," Journal of Hydraulic Engineering, vol. 138, no. 5, pp. 471474, 2012.

[5] M. J. Uddin, M. M. Hossain, and M. S. Ali, "Local scour around submerged bell mouth groin for different orientations," Journal of Civil Engineering, vol. 39, no. 1, pp. 1-18, 2011.

[6] H. K. Yeo, J. G. Kang, and S. J. Kim, "An experimental study on tip velocity and downstream recirculation zone of single groynes of permeability change," KSCE Journal of Civil Engineering, vol. 9, no. 1, pp. 29-38, 2005.

[7] N. Rajaratnam and B. A. Nwachukwu, "Flow near groin-like structures," Journal of Hydraulic Engineering, vol. 109, no. 3, pp. 463-480, 1983.

[8] M. S. Ali, T. Hosoda, and I. Kimura, "Unsteady RANS and les simulation of an ideal Rankine vortex decay," Advances in Civil Engineering, vol. 2012, Article ID 523839, 8 pages, 2012.

[9] M. S. Ali, Model Refinements of Unsteady RANS and Its Practical Applications in the Field of Hydraulic Engineering [Ph.D. thesis], Department of Urban Management, Kyoto University, Japan, 2008.

[10] S. Y. Jaw and C. J. Chen, "Present status of second-order closure turbulence models. I: overview," Journal of Engineering Mechanics, vol. 124, no. 5, pp. 485-501, 1998.

[11] M. S. Ali, T. Hosoda, and I. Kimura, "Development of a nonlinear $k-\varepsilon$ model incorporating strain and rotation parameters for prediction of complex turbulent flows," International Journal of Partial Differential Equations, Art. ID 105809, 15 pages, 2015.

[12] I. Kimura, W. S. J. Uijttewaal, T. Hosoda, and M. S. Ali, "URANS computations of shallow grid turbulence," Journal of Hydraulic Engineering, vol. 135, no. 2, pp. 118-131, 2009.

[13] W. Rodi, Turbulence models for environmental problems, Prediction Methods for Turbulent Flows, (1979).

[14] iRIC (2013) Nays 2D, International River Interface Cooperative, Hokkaido Univ., Japan, http://i-ric.org/en/introduction.

[15] C.-L. Jang and Y. Shimizu, "Numerical simulation of relatively wide, shallow channels with erodible banks," Journal of Hydraulic Engineering, vol. 131, no. 7, pp. 565-575, 2005.

[16] I. Kimura and T. Hosoda, "A non-linear k- $\varepsilon$ model with realizability for prediction of flows around bluff bodies," International Journal for Numerical Methods in Fluids, vol. 42, no. 8, pp. 813837, 2003.

[17] L. Quanhong and L. Pengzhi, "Numerical simulation of recirculating flow near a groyne," in Proceedings of the The 2nd International Conference on Marine Research and Transportation, pp. 61-68, Ischia, Naples, Italy, 2007. 


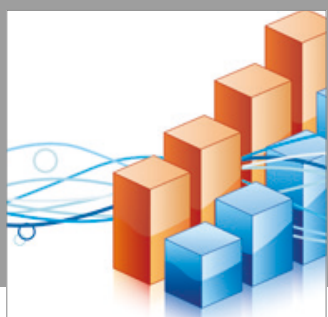

Advances in

Operations Research

vatersals

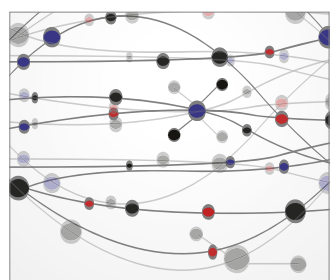

\section{The Scientific} World Journal
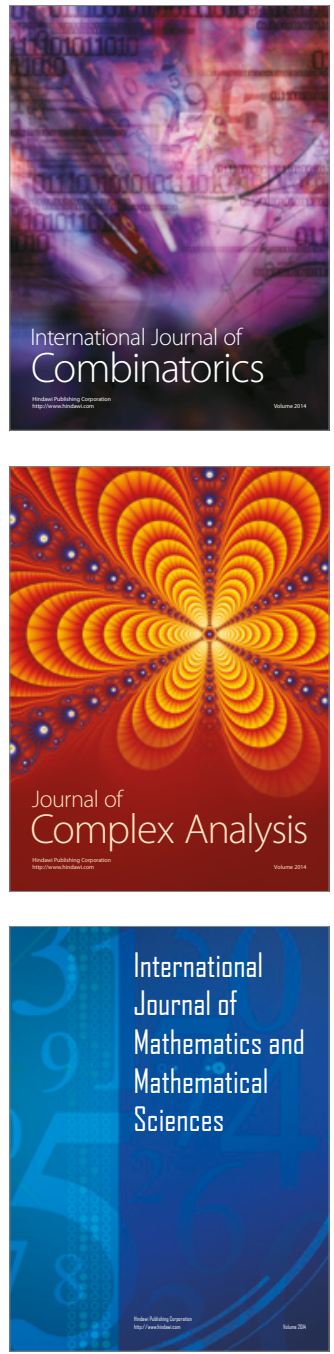
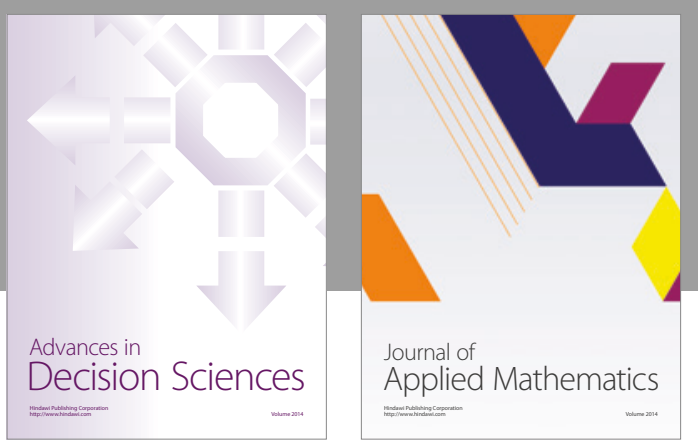

Algebra

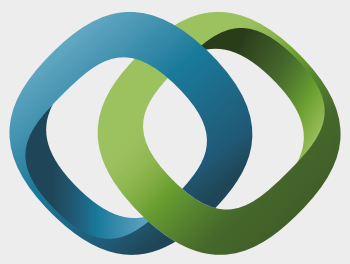

\section{Hindawi}

Submit your manuscripts at

https://www.hindawi.com
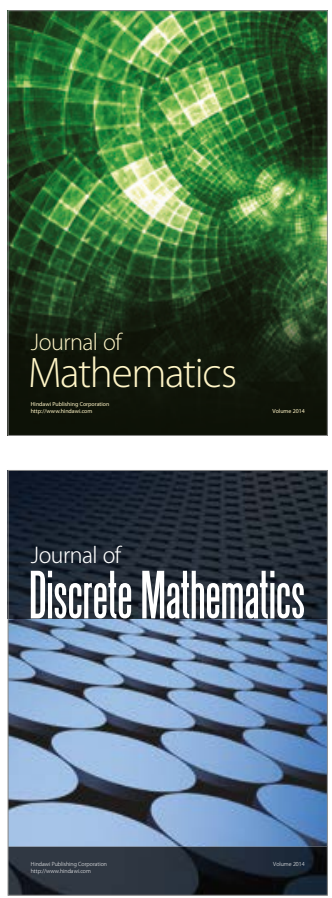

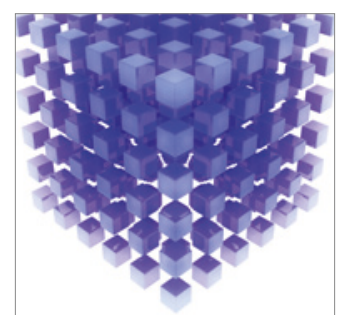

Mathematical Problems in Engineering
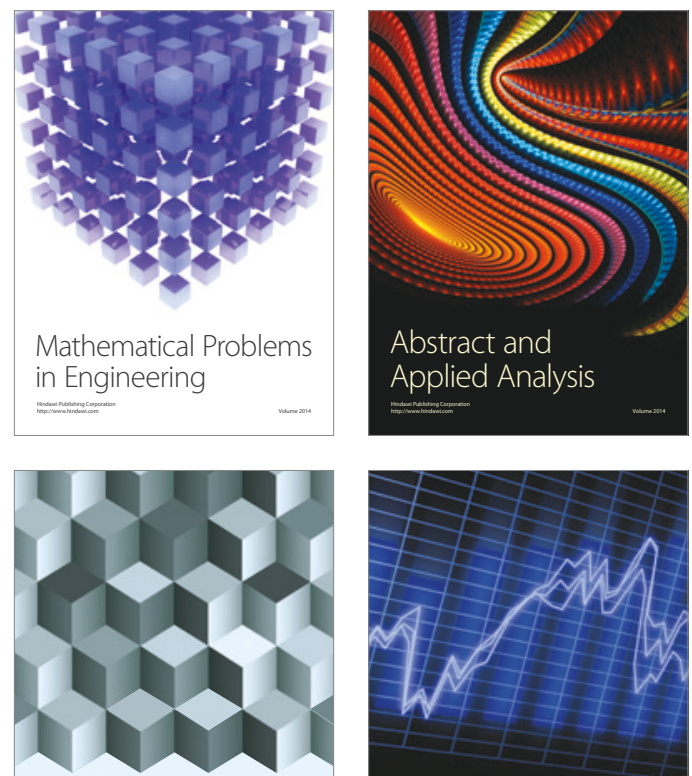

Journal of

Function Spaces

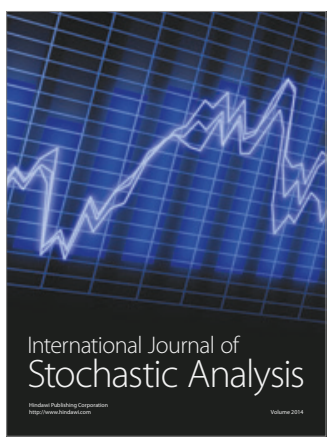

Probability and Statistics
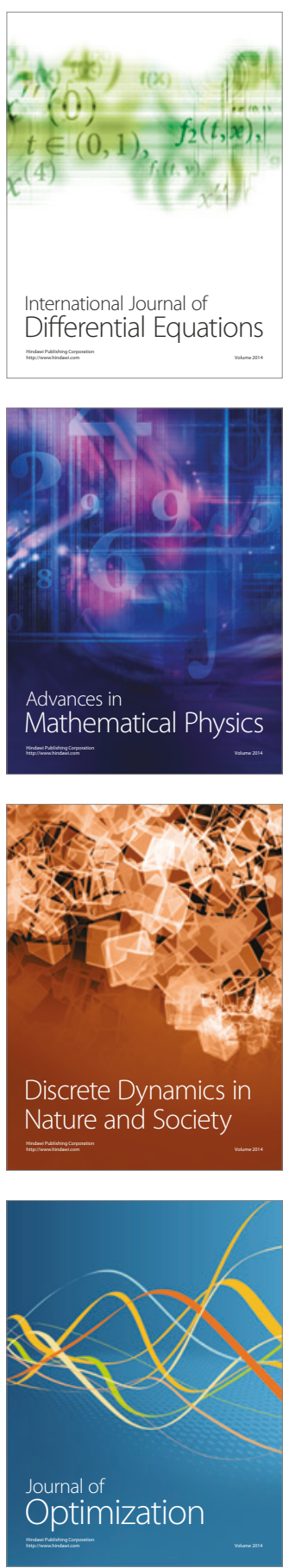